\title{
Effect of core stabilization exercises on functional disability in patients with chronic low back pain
}

\author{
Amila Kapetanovic ${ }^{1 *}$, Sabina Jerkovic², Dijana Avdic ${ }^{3}$
}

${ }^{1}$ Institution for Medical Rehabilitation and Spa Therapy Reumal, Fojnica, Bosnia and Herzegovina, ${ }^{2}$ General Hospital Prim. Dr. Abdulah Nakaš, Sarajevo, Bosnia and Herzegovina, ${ }^{3}$ Faculty of Health Studies, University of Sarajevo, Sarajevo, Bosnia and Herzegovina

\begin{abstract}
Introduction: The aim of this study was to assess core stabilization exercise effects in reducing functional disability in patients with chronic low back pain (CLBP).

Methods: This study included total of 90 patients aged 40 to 60 years. After a ten-day rehabilitation program the patients from an examination group $(n=30)$ performed home exercise program five times a week, patients from a first control group $(n=30)$ three times a week, while patients from a second control group $(n=30)$ did not perform the exercises at all. The patients performed core stabilization exercises of moderate intensity once a day in 30 minutes sessions. The patient's functional disability was estimated using the Oswestry Disability Index (ODI).
\end{abstract}

Results: After two months of rehabilitation there was a statistically significant increase in functional ability in patients who performed the core stabilization exercises five times a week $(p=0.0001)$ and in patients who performed the core stabilization exercises three times per week $(p=0.0001)$. A statistically significant difference in functional ability was not recorded in patients who did not perform the exercises. The analysis of the average values of the ODI differences at the beginning and after two months of rehabilitation showed a statistically significant difference between the group who did not perform the exercises and the group who performed the core stabilization exercises three times a week $(p=0.0001)$, and between the group who did not perform the exercises and the group who performed the core stabilization exercises five times a week $(p=0.0001)$.

Conclusions: The implementation of the core stabilization exercises leads to a reduction of functional disability in patients with CLBP.

Keywords: core stabilization exercises; chronic low back pain; disability; functional

\footnotetext{
*Corresponding Author: Amila Kapetanovic, Institution for Medical Rehabilitation and Spa therapy Reumal,

Fojnica, Bosnia and Herzegovina.

E-mail: nermin1a@bih.net.ba
}

Submitted: 01 March 2016 / Accepted: 05 April 2016

DOI: http://dx.doi.org/10.17532/jhsci.2016.346

UNIVERSITY OF SARAJEVO FACULTY OF HEALTH STUDIES

\section{INTRODUCTION}

Low back pain (LBP) affects many individuals and results in significant level of disability, producing significant restriction on usual activity, affects work performance and social responsibilities $(1,2)$. It is increasingly a major factor in escalating health-care costs (1). LBP was shown to be a major problem 
throughout the world, the prevalence was estimated to be $11.9 \pm 2.0 \%$, and the 1 -month prevalence was estimated to be $23.2 \pm 2.9 \%$ (systematic review of the global prevalence of low back pain that included general population studies published between 1980 and 2009) (3).

The clinical course of LBP can be described as acute, subacute, recurrent, or chronic (4). Clinicians should conduct a focused history and physical examination to help place patients with LBP into 1 of 3 broad categories: nonspecific low back pain (NSLBP), back pain potentially associated with radiculopathy or spinal stenosis, or back pain potentially associated with another specific spinal cause (5).

Exercise therapy is recommended and is the most widely used type of conservative treatment for LBP $(6,7)$. The research has shown that exercise therapy is not effective for the treatment of acute low back pain (7-9). In subacute low back pain populations, some evidence suggests that a graded activity program improves absenteeism outcomes, although evidence for other types of exercise is unclear (9). The evidence from randomized controlled trials demonstrated that exercise therapy is effective at reducing pain and improving function in the treatment of chronic low back pain (CLBP) (7). Many exercise techniques have been developed for the treatment of CLBP. Their aims are pain decrease, muscular strengthening in flexion or extension, increased hip and lumbar spine mobility, improved lumbar and pelvic proprioceptive sensibility (10), improved motor control and muscle capacity (11), improved performance of endurance activities, reduced back pain-related disability (12), and improved general fitness (10).

Consensus on the most effective types of exercises for the treatment of CLBP has not been reached yet. The results of the studies which were aimed to examine the effectiveness of certain types of exercises in the rehabilitation of patients with CLBP vary. Some studies showed that there is a difference in the effectiveness of kinesiotherapy programs, depending on the type of the exercises. However, in other studies this was not confirmed or was simply disregarded. Besides a type of the exercises, a kinesiotherapy program need to be defined by other parameters as well. Exercise programs may vary in terms of duration, frequency, and dosage; whether they are supervised; and whether they include a home-based program (13).

Stabilization exercises were developed based on the theory of spinal dysfunction proposed by Panjabi and on an anatomical and biomechanical model of trunk muscle function proposed by Bergmark (14). The spinal stabilizing system consists of three subsystems (Panjabi's stability model): the passive subsystem (the vertebrae, discs, and ligaments), active subsystem (all muscles and tendons surrounding the spinal column that can apply forces to the spinal column), and the neural subsystem (the nerves and central nervous system, the neural control unit) $(15,16)$. The neutral zone (a region of intervertebral motion around the neutral posture where little resistance is offered by the passive spinal column) appears to be a clinically important measure of spinal stability function, it may increase with injury to the spinal column or with weakness of the muscles, which in turn may result in spinal instability or a low-back problem (17). Under normal conditions, the three subsystems work in harmony and provide the needed mechanical stability (16). Either one of the subsystems, separately or together, may not function appropriately, and thus affect the overall stability of the spinal system (15). Spine stability is the basic requirement to protect nervous structures and prevent the early mechanical deterioration of spinal components (18). The normal function of the stabilizing system is to provide sufficient stability to the spine to match the instantaneously varying stability demands due to changes in spinal posture, and static and dynamic loads (15).

The "muscle capacity" model of core stability exercise is based on the well-established premise that stability of the spine is dependent on the contribution of muscles (11). Muscular based stability of the trunk is often referred to as "core" stability (19). The so-called core is the group of trunk muscles that surround the spine and abdominal viscera; abdominal, gluteal, hip girdle, paraspinal, and other muscles work in concert to provide spinal stability (20).

Stabilization exercises have been used to treat patients with segmental instability, clinical instability, and chronic pain (14).

LBP is a challenge for clinicians and researchers, due to the large variability in clinical presentation, lack 
of consensus regarding diagnostic criteria or clinical classification, wide variation in course and prognosis, and limited success in identifying effective treatments (21).

The aim of this study was to assess the treatment effect of stabilization exercises for reducing functional disability in patients with CLBP.

\section{METHODS}

\section{Study design}

This prospective clinical study included a total of 90 patients aged 40 to 60 years.

The patients who met following criteria were included into the study: respondents aged 40 to 60 years, respondents with CLBP/without serious spinal pathology or specific diseases, with no signs of damage to the nerve roots, respondents who conducted a ten-day physical therapy that included electrotherapy, hydrotherapy, and core stabilization exercises and who had been trained to implement core stabilization exercises at home, respondents who after the ten-day physical therapy program conducted core stabilization exercises at home five times a week, respondents who after the ten-day physical therapy program conducted core stabilization exercises at home three times a week, respondents who after the ten-day physical therapy program did not conduct core stabilization exercises at home. The exclusion criteria were: respondents younger than 40 and older than 60 years, respondents without CLBP, respondents with suspected serious spinal pathology, and respondents with signs of damage to the nerve roots.

After the ten-day rehabilitation program (electrotherapy, hydrotherapy, core stabilization exercises) at the Department for Physical Medicine and Rehabilitation of General Hospital Prim. Dr. Abdulah Nakaš in Sarajevo, the patients from an examination group $(\mathrm{n}=30)$ performed the home based exercises program five times a week, the patients from a first control group $(\mathrm{n}=30)$ three times a week, and the patients from a second control group $(\mathrm{n}=30)$ did not perform the exercises program at all.

The patients received ten days training, in the hospital, on how to implement the core stabilization exercises program at home.
The patients performed the core stabilization exercises (1. Neutral Spine; 2. Cat - Camel; 3. Curl - up; 4. Birddog; 5. Side Bridge; 6. Prone Bridge; 7. Supine Bridge), once a day, the intensity was moderate, the duration of one session was 30 minutes.

The patient's functional disability was estimated at the beginning of the rehabilitation and two months later, using the Oswestry Low Back Pain Disability Questionnaire/The Oswestry Disability Index (ODI). The ODI contains ten sections: pain intensity, personal care, lifting, walking, sitting, standing, sleeping, sex life, social life, and travelling. Each of the ten sections is valued from 0 to 5 points. The possible total ODI score is 50 , and higher scores mean higher functional disability.

\section{Statistical analysis}

Results of the analysis are presented in the tables and graphs. We used the nonparametric hypothesis tests: the Chi-square test, one-way analysis of variance (ANOVA) and Student $t$ test. The results of these tests were considered statistically significant at a confidence level of $95 \%$ or with $\mathrm{p}<0.05$. Statistical analysis was performed by using the statistical package IBM SPSS Statistics v21.0 (Chicago, Illinois, USA), while the presentation of results (tables and graphs) was created by using Microsoft Office Word and Excel 2007 (Redmond, California, USA).

\section{RESULTS}

We had three groups of participants with 30 members in each and there were no statistically significant differences in average age between the groups $(\mathrm{p}>0.05)$ (Table 1$)$. In all the three groups male respondents were over-represented, with no statistically significant differences between the groups (p > 0.05) (Table 2).

Comparison of the average scores of the ODI before the rehabilitation shows that there are no statistically significant differences observed between the groups by the one-way analysis of variance ANOVA $(\mathrm{p}>0.05)$ (Table 3). A somewhat higher average score before the rehabilitation was observed in the group of the patients without kinesiotherapy (24.03 \pm 2.7 ), while the lowest score was recorded in the group of the patients with kinesiotherapy $5 \mathrm{x}(23.37$ \pm 3.4 ) (Table 3, Figure 1). 
TABLE 1. Comparison of average age by the groups

\begin{tabular}{lcccccc}
\hline & $\mathrm{N}$ & $\mathrm{X}$ & $\mathrm{SD}$ & $\mathrm{SE}$ & Minimum & Maximum \\
\hline Kinesiotherapy 3x & 30 & 46.533 & 5.0016 & 0.9132 & 40 & 58 \\
Kinesiotherapy 5x & 30 & 47.000 & 4.5637 & 0.8332 & 40 & 56 \\
Without kinesiotherapy & 30 & 47.267 & 5.0850 & 0.9284 & 40 & 60 \\
Total & 90 & 46.933 & 4.8432 & 0.5105 & 40 & 60 \\
\hline
\end{tabular}

$F=0.173 ; p=0.841$ ( $p>0.05) ;$ SD: Standard deviation; SE: Standard error

TABLE 2. Comparison of gender distribution in the groups

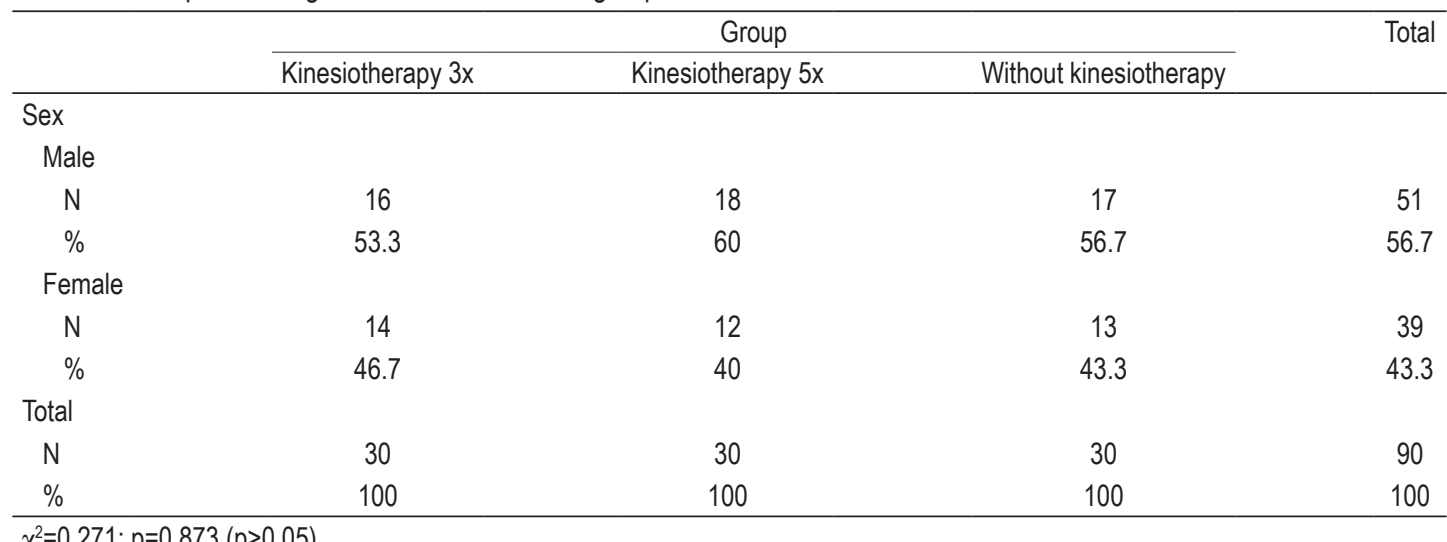

TABLE 3. Average values of oswestry disability index before treatment and comparison between the groups

\begin{tabular}{lcccccc}
\hline & $\mathrm{N}$ & $\mathrm{X}$ & $\mathrm{SD}$ & $\mathrm{SE}$ & Minimum & Maximum \\
\hline ODI before treatment & & & & & & \\
Kinesiotherapy 3X & 30 & 23.533 & 3.0256 & 0.5524 & 18 & 30 \\
Kinesiotherapy 5x & 30 & 23.367 & 3.4289 & 0.6260 & 18 & 30 \\
Without kinesiotherapy & 30 & 24.033 & 2.6844 & 0.4901 & 21 & 30 \\
Total & 90 & 23.644 & 3.0402 & 0.3205 & 18 & 30 \\
\hline
\end{tabular}

$\mathrm{F}=0.385 ; \mathrm{P}=0.681$, ODI: Oswestry disability index ; SD: Standard deviation; SE: Standard error

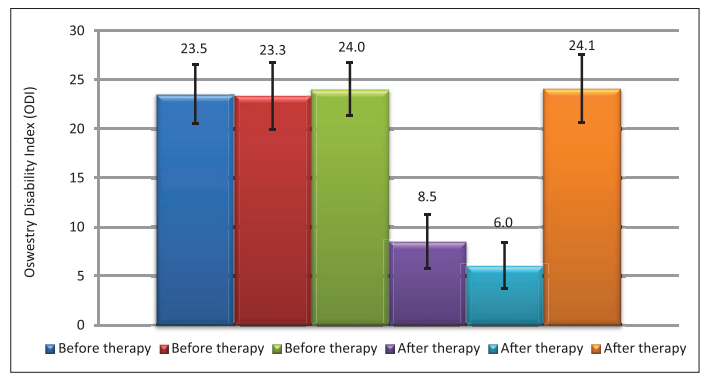

FIGURE 1. Average values of the oswestry disability index before and after treatment.

The highest average score of the ODI after the rehabilitation was observed in the group of the patients who did not perform the program of kinesiotherapy
(24.1 \pm 3.46$)$, much lower in the group of the patients who had kinesiotherapy $3 x(8.5 \pm 2,78)$, and the lowest in the group of the patients with kinesiotherapy 5x $(6.03 \pm 2.34)$ (Table 4, Figure 1). Comparison of the average values of the ODI before and after the rehabilitation observed by the Student $t$ test showed that a statistically significant difference was observed in the group of the patients who had kinesiotherapy $3 x(p=0.0001)$ and kinesiotherapy $5 \mathrm{x}(\mathrm{p}=0.0001)$, but not in the group without kinesiotherapy $(\mathrm{p}=0.889)$ (Table 5).

The maximum value of the average difference of the ODI after and before the rehabilitation was observed in the group of the patients who had kinesiotherapy 
TABLE 4. Average values of oswestry disability index after treatment

\begin{tabular}{lcccccc}
\hline & $\mathrm{N}$ & $\mathrm{X}$ & $\mathrm{SD}$ & $\mathrm{SE}$ & Minimum & Maximum \\
\hline ODI after treatment & & & & & & \\
Kinesiotherapy 3X & 30 & 8.500 & 2.7761 & 0.5068 & 3 & 14 \\
Kinesiotherapy 5X & 30 & 6.033 & 2.3413 & 0.4275 & 1 & 10 \\
Without kinesiotherapy & 30 & 24.100 & 3.4676 & 0.6331 & 19 & 31 \\
Total & 90 & 12.878 & 8.5392 & 0.9001 & 1 & 31 \\
\hline
\end{tabular}

ODI: Oswestry disability index; SD: Standard deviation; SE: Standard error

TABLE 5. Comparison of the average values of the oswestry disability index before and after treatment (student $t$-test)

\begin{tabular}{lcc}
\hline & $t$ & $p$ \\
\hline Kinesiotherapy 3x & 25.995 & 0.0001 \\
Kinesiotherapy 5x & 26.273 & 0.0001 \\
Without kinesiotherapy & -0.141 & 0.889 \\
\hline
\end{tabular}

$5 x(-17.33 \pm 3.6)$, followed by the difference in the group of the patients who had kinesiotherapy $3 \mathrm{x}(-15.03 \pm 3.17)$, while in the group of the patients without kinesiotherapy a slight increase was recorded $(0.07 \pm 2.6)$ (Table 6 , Figure 2$)$.

The analysis of the average values of the ODI differences after two months of the rehabilitation and at the beginning of the rehabilitation showed a statistically significant difference between the group of the patients who did not perform kinesiotherapy at home and the group of the patients who performed kinesiotherapy at home three times a week $(\mathrm{p}=0.0001)$, and between the group of the patients who did not perform kinesiotherapy at home and the group of the patients who performed kinesiotherapy at home five times a week $(\mathrm{p}=0.0001)$ (Table 7).

\section{DISCUSSION}

Individual exercise programs may differ from one another in a number of ways, such as duration, dosage, exercise type, the extent of supervision, the inclusion of behavioral principles, and the inclusion of a home-based program (13). This study examined the impact of a kinesiotherapy program that was defined by the type of exercises (core stabilization), the intensity of exercise (moderate), duration of a single session (30 minutes), and the frequency of the implementation of exercise (once a day) on the functional ability of people with CLBP that was not caused by a serious

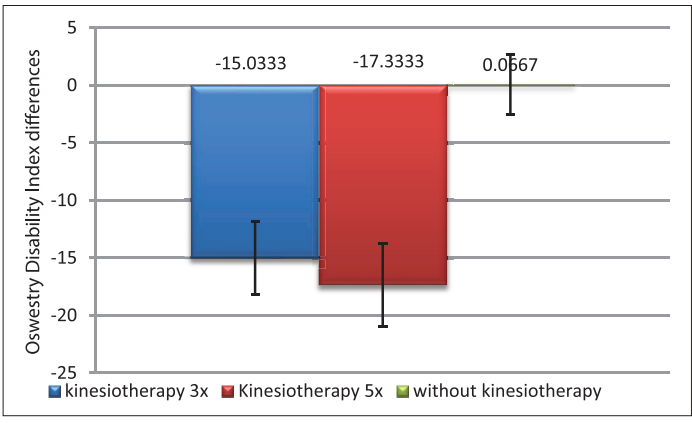

FIGURE 2. Average values of the oswestry disability index differences before and after treatment.

spinal pathology or specific disease and was not accompanied by the signs of damage to the nerve roots.

The results of the researches which were aimed to examine the effectiveness of certain types of exercises in the rehabilitation of patients with CLBP vary. The purpose of the study of Inani and Selkar was to determine the effect of core stabilization exercises in comparison with conventional exercises on pain and functional status in patients with NSLBP. Core stabilization exercises were found to be more effective in reducing pain and improving functional status by decreasing disability of patients with NSLBP in comparison with conventional exercises (2). The lumbar stabilization exercises were found to be more effective in lumbar extensor strengthening and functional improvement in patients with NSLBP in comparison with dynamic strengthening exercises (22). França et al. compared the effects of two exercise programs, segmental stabilization exercises and stretching of trunk and hamstrings muscles on functional disability, pain, and activation of the transversus abdominis muscle in individuals with CLBP. Both techniques improved pain and reduced disability, but segmental stabilization exercises were 
TABLE 6. Average values of the oswestry disability index differences before and after treatment

\begin{tabular}{lcccccc}
\hline & $\mathrm{N}$ & $\mathrm{X}$ & $\mathrm{SD}$ & $\mathrm{SE}$ & Minimum & Maximum \\
\hline Kinesiotherapy 3x & 30 & -15.0333 & 3.16754 & 0.57831 & -21.00 & -10.00 \\
Kinesiotherapy 5x & 30 & -17.3333 & 3.61351 & 0.65973 & -25.00 & -10.00 \\
Without kinesiotherapy & 30 & 0.0667 & 2.59885 & 0.47448 & -5.00 & 5.00 \\
Total & 90 & -10.7667 & 8.36398 & 0.88164 & -25.00 & 5.00 \\
\hline
\end{tabular}

SD: Standard deviation; SE: Standard error

TABLE 7. Comparison of the average values of the Oswestry Disability Index differences between the groups, before and after treatment (Student t-test)

\begin{tabular}{lcc}
\hline & $\mathrm{t}$ & $\mathrm{p}$ \\
\hline Without kinesiotherapy: kinesiotherapy 3x & 20.186 & 0.0001 \\
Without kinesiotherapy: kinesiotherapy 5x & 21.412 & 0.0001 \\
\hline
\end{tabular}

superior to muscular stretching for the measured variables associated with CLBP (23). Kaljić et al. found that treatment with trunk stabilizing exercises leads to improved condition of patients with CLBP (24). A systematic review of clinical randomized controlled trials conducted by Kriese et al. showed that segmental stabilizing exercises are more effective than a minimal intervention, but they are not more effective than other physiotherapy interventions in the treatment of LBP (25). The aim of the systematic review update of Smith et al. was to investigate the effectiveness of stabilization exercises for the treatment of NSLBP, and compare any effectiveness to other forms of exercise. There was strong evidence that stabilization exercises are not more effective than any other form of active exercise in the long term (26).

Based on a solid biomechanical model (Panjabi's hypotheses) stabilization exercises have demonstrated positive effects over pain and return to activity, but other variables are not clear (27).

A consensus has not been reached among strength and conditioning specialists regarding what physical fitness exercises are most effective to stimulate the activity of the core muscles (28).

Patients included in our study had been conducting following exercises: Neutral Spine, Cat - Camel, Curl - up, Birddog, Side bridge, Prone Bridge, Supine Bridge.

In his study, Bruno states that there is evident lack of clinical trials that make direct comparison of a program focused on the selective activation of the deep muscles with a program focused on the contraction of all abdominal and low back musculature (29). Brumitt et al. find that stabilization exercises for patients with LBP may help to decrease pain and disability and that it may not be necessary to prescribe exercises purported to restore the motor control of specific muscles (30). Several recent rehabilitative approaches emphasize the re-training of functional movement patterns as part of a "stabilization exercise" program, rather than focusing efforts on training specific muscles (29).

Besides the type of exercise, the kinesiotherapy program should also be defined by other parameters (dosage, frequency, duration, supervision/ home based). Sandler et al. showed that those who reported using weight training machines, as part of muscle-strengthening activities, had a higher risk of reporting LBP, compared with those who did not perform muscle-strengthening activities or performed calisthenic or free weight activities (31). Aleksiev found the exercise frequency is more important than the type, duration, or intensity of the exercise in the long-term treatment of recurrent low back pain (32). The results of the study of Ferreira et al. show that when different types of exercises are analyzed, small but significant reductions in pain and disability are observed compared with minimal care or no treatment and despite many possible sources of heterogeneity in exercise trials, only dosage was found to be significantly associated with effect sizes (13).

Results of this study showed that after two months of rehabilitation there was a statistically significant increase in functional ability in the patients who implemented the core stabilization exercises at home five times a week $(p=0.0001)$ and in the patients who implemented the core stabilization exercises at home three times per week 
$(\mathrm{p}=0.0001)$. A statistically significant difference in functional ability was not recorded in the patients who did not implement the core stabilization exercises at home. The analysis of the average values of the ODI differences after two months of the rehabilitation and at the beginning of the rehabilitation showed a statistically significant difference between the group of the patients who did not perform the kinesiotherapy at home and the group of the patients who performed the stabilization exercises at home three times a week $(\mathrm{p}=0.0001)$, and between the group of the patients who did not perform the kinesiotherapy at home and the group of the patients who performed the stabilization exercises at home five times a week $(p=0.0001)$.

\section{CONCLUSION}

Core stabilization exercises, implemented through a structured home exercise program, lead to reduced functional disability in patients with chronic low back pain.

\section{CONFLICT OF INTEREST}

Authors declare no conflict of interest.

\section{REFERENCES}

1. Manchikanti L, Singh V, Falco FJ, Benyamin RM, Hirsch JA. Epidemiology of low back pain in adults. Neuromodulation. 2014;17 Suppl 2:3-10. http://dx.doi.org/10.1111/ner.12018

2. Inani SB, Selkar SP. Effect of core stabilization exercises versus conventional exercises on pain and functional status in patients with non-specific low back pain: a randomized clinical trial. J Back Musculoskelet Rehabil. 2013;26(1):37-43.

DOI: 10.3233/BMR-2012-0348.

3. Hoy D, Bain C, Williams G, March L, Brooks P, Blyth F, et al. A systematic review of the global prevalence of low back pain. Arthritis Rheum. 2012;64(6):2028-37. http://dx.doi.org/10.1002/art.34347.

4. Delitto A, George SZ, Van Dillen LR, Whitman JM, Sowa G, Shekelle P, et al. Low back pain. J Orthop Sports Phys Ther. 2012;42(4):A1-57. http://dx.doi.org/10.2519/jospt.2012.42.4.A1.

5. Chou R, Qaseem A, Snow V, Casey D, Cross T, Shekelle P, et al. Diagnosis and treatment of low back pain: a joint clinical practice guideline from the American College of Physicians and the American Pain Society. Ann Intern Med. 2007;147(7):478-91. http://dx.doi.org/10.7326/0003-4819-147-7-200710020-00006

6. Rasmussen-Barr E, Ang B, Arvidsson I, Nilsson-Wikmar L. Graded exercise for recurrent low-back pain: a randomized, controlled trial with 6-, 12-, and 36-month follow-ups. Spine (Phila Pa 1976). 2009;34(3):221-8. http://dx.doi.org/10.1097/BRS.0b013e318191e7cb.

7. Middelkoop M, Rubinstein SM, Verhagen AP, Ostelo RW, Koes BW, van Tulder MW. Exercise therapy for chronic nonspecific low-back pain. Best
Pract Res Clin Rheumatol. 2010 24(2):193-204.

http://dx.doi.org/10.1016/j.berh.2010.01.002

8. Van Tulder M, Malmivaara A, Esmail R, Koes B. Exercise therapy for low back pain: a systematic review within the framework of the cochrane collaboration back review group. Spine (Phila $\mathrm{Pa}$ 1976) 2000 Nov 1;25(21):2784-96 http://dx.doi.org/10.1097/00007632-200011010-00011.

9. Hayden JA, van Tulder MW, Malmivaara AV, Koes BW. Meta-analysis: exercise therapy for nonspecific low back pain. Ann Intern Med. 2005;142(9):765-75. http://dx.doi.org/10.7326/0003-4819-142-9-200505030-00013

10. Poiraudeau S, Lefevre-Colau MM, Mayoux-Benhamou MA Revel M. Which rehabilitation for which low back pain? Rev Prat. 2000:50(16):1779-83.

11. Hodges PW. Core stability exercise in chronic low back pain. Orthop Clin N Am. 2003; 34(2):245-54

http://dx.doi.org/10.1016/S0030-5898(03)00003-8.

12. Rainville J, Hartigan C, Martinez E, Limke J, Jouve C, Finno M. Exercise as a treatment for chronic low back pain. Spine J. 2004;4(1):106-15.

13. Ferreira ML, Smeets RJ, Kamper SJ, Ferriera PH, Machado LA. Can we explain heterogeneity among randomized clinical trials of exercise for chronic back pain? A meta-regression analysis of randomized controlled trials. Phys Ther. 2010;90(10):1383-403. http://dx.doi.org/10.2522/ptj.20090332.

14. Biely S, Smith SS, Silfies SP. Clinical instability of the lumbar spine: diagnosis and intervention. Orthopaedic Practice. 18:3:06.

15. Panjabi MM. The stabilizing system of the spine. Part I. Function, dysfunction, adaptation, and enhancement. J Spinal Disord. 1992;5(4):383- 9.

16. Panjabi MM. Clinical spinal instability and low back pain. J Electromyogr Kinesiol. 2003;13(4):371- 9 http://dx.doi.org/10.1016/S1050-6411(03)00044-0.

17. Panjabi MM. The stabilizing system of the spine. Part II. Neutral zone and instability hypothesis. J Spinal Disord. 1992;5(4):390- 6

18. Izzo R, Guarnieri G, Guglielmi G, Muto M. Biomechanics of the spine. Part I: spinal stability. Eur J Radiol. 2013;82(1):118-26. http://dx.doi.org/10.1016/j.ejrad.2012.07.024

19. Neumann DA. Kinesiology of the musculoskeletal system: foundations for rehabilitation. St. Louis, Missouri: Mosby, Elsevier; 2010.

20. AkuthotaV, Ferreiro A, Moore T, Fredericson M. Core stability exercise principles. Curr Sports Med Rep. 2008;7(1):39-44. DOI: 10.1097/01.CSMR.0000308663.13278.69.

21. Van der Windt DA, Dunn KM. Low back pain research-future directions. Best Pract Res Clin Rheumatol. 2013;27(5):699-708. http://dx.doi.org/10.1016/j.berh.2013.11.001.

22. Moon HJ, Choi KH, Kim DH, Cho YK, Lee KH, Choi YJ. Effect of lumba stabilization and dynamic lumbar strengthening exercises in patients with chronic low back pain. Ann Rehabil Med. 2013;37(1):110-7. http://dx.doi.org/10.5535/arm.2013.37.1.110

23. França FR, Burke TN, Caffaro RR, Ramos LA, Marques AP. Effects of muscular stretching and segmental stabilization on functional disability and pain in patients with chronic low back pain: a randomized, controlled trial. J Manipulative Physiol Ther. 2012;35(4):279-85. http://dx.doi.org/10.1016/j.jmpt.2012.04.012.

24. Kaljić E, Avdić D, Pecar M, Trtak N, Katana B, Kaljić N. Efficiency of trunk stabilizing exercises in treatment of patients with lumbar pain syndrome. Journal of Health Sciences 2013;3(3):216-21. http://dx.doi.org/10.17532/jhsci.2013.110.

25. Kriese M, Clijsen R, Taeymans J, Cabri J. Segmental stabilization in low back pain: a systematic review [Article in German]. Sportverletz Sportschaden. 2010;24(1):17-25. http://dx.doi.org/10.1055/s-0030-1251512.

26. Smith BE, Littlewood C, May S. An update of stabilisation exercises for low 
back pain: a systematic review with meta-analysis. BMC Musculoskelet Disord. 2014;15(1):416.

http://dx.doi.org/10.1186/1471-2474-15-416.

27. Luque-Suárez A, Díaz-Mohedo E, Medina-Porqueres I, PonceGarcía T. Stabilization exercise for the management of low back pain. In: Ali Asghar Norasteh, editor. Low back pain. InTech; 2012. Available from InTech: http://www.intechopen.com/books/low-back-pain/ exercise-therapy-for-the-management-of-low-back-pain.

28. Martuscello JM, Nuzzo JL, Ashley CD, Campbell BI, Orriola JJ, Mayer, JM Systematic review of core muscle activity during physical fitness exercises. J Strenght Cond Res. 2013;27(6):1684-98. http://dx.doi.org/10.1519/JSC.0b013e318291b8da.

29. Bruno P. The use of "stabilization exercises" to affect neuromuscular control in the lumbopelvic region: a narrative review. J Can Chiropr Assoc.

\section{4;58(2):119-30.}

30. Brumitt J, Matheson JW, Meira EP. Core stabilization exercise prescription, part 2: a systematic review of motor control and general (global) exercise rehabilitation approaches for patients with low back pain. Sports Health. 2013;5(6):510-3.

http://dx.doi.org/10.1177/1941738113502634.

31. Sandler RD, Sui X, Church TS, Fritz SL, Beattie SN, Blair SN. Are flexibility and muscle-strengthening activities associated with a higher risk of developing low back pain? J Sci Med Sport. 2014;17(4):361-5. http://dx.doi.org/10.1016/j.jsams.2013.07.016.

32. Aleksiev AR. Ten-year follow-up of strengthening versus flexibility exercises with or without abdominal bracing in recurrent low back pain. Spine (Phila Pa 1976). 2014;39(13):997-1003. http://dx.doi.org/10.1097/BRS.0000000000000338. 